\title{
Feedback and assessment for clinical placements: achieving the right balance
}

This article was published in the following Dove Press journal:

Advances in Medical Education and Practice

19 May 2015

Number of times this article has been viewed

\section{Annette Burgess \\ Craig Mellis}

Central Clinical School, Sydney Medical School, The University of Sydney, Sydney, NSW, Australia
Correspondence: Annette Burgess Central Clinical School, Sydney Medical School, The University of Sydney, Building 63, Level 4, Royal Prince Alfred Hospital, Missenden Road, Camperdown, Sydney, NSW 2050, Australia

Tel +6I 295158172

Email annette.burgess@sydney.edu.au
Abstract: During clinical placements, the provision of feedback forms an integral part of the learning process and enriches students' learning experiences. The purpose of feedback is to improve the learner's knowledge, skills, or behavior. Receipt of accurate feedback can help to narrow the gap between actual and desired performance. Effective and regular feedback has the potential to reinforce good practice and motivate the learner toward the desired outcome. Despite the obvious role of feedback in effective teaching and learning, a common complaint from students is that they do not receive adequate feedback. Unfortunately, skills in giving and receiving feedback are rarely taught to students or clinicians. This study aims to provide an understanding of the role of feedback within the learning process, consider consequences of inadequate or poorly given feedback, consider the barriers to the feedback process, provide practical guidelines for providing feedback, and consider the need for student and faculty development in feedback skills.

Keywords: medical students, formative, summative, assessment

\section{Introduction}

Within clinical education, feedback has been described as "Specific information about the comparison between a trainee's observed performance and a standard, given with the intent to improve the trainee's performance." For feedback to be of value, some observation, or assessment, is a prerequisite. Assessment and feedback can be either formative or summative. Formative has the specific purpose of improving the learner's knowledge, skills, or behavior. Summative assessment means a judgment is made about the learner's performance and on whether progression occurs (ie, "barrier assessment"). Feedback is an integral part of the learning process, allowing the student to stay on course in reaching the required outcomes.

In clinical placements, medical students are attached to a hospital ward or medical team, usually for a period of four weeks. The provision of feedback offers a valuable method of enriching the students' learning experience. Receipt of accurate feedback can help to narrow the gap between actual and desired performance. ${ }^{2}$ Despite the obvious role of feedback in effective teaching and learning, a common complaint from students is that they do not receive adequate feedback.

Clinical skills, such as taking a patient history or performing a physical examination, synthesizing, and presenting this information, represent a compilation of numerous cognitive and psychomotor skills and behaviors. Consequently, clinical skills are more easily demonstrated, rather than described. Unfortunately, direct observation of 
these skills during clinical placements is infrequent, thus preventing supervisors from giving feedback. None of this is surprising, given that during clinical placements, most teaching is by busy clinicians, who are not trained as teachers. Although giving feedback is an essential component of a lifelong career in medicine, nursing, and many other health professions, it is a skill seldom taught in university or at the workplace. ${ }^{3-5}$ Clearly, we need to provide training in the use of an effective methodical approach to giving feedback in the clinical setting.

It has been widely reported that medical students are rarely directly observed, assessed, and given feedback during their clinical placements. ${ }^{2}$ Accordingly, there has been an increased interest in a variety of formative assessment methods that specifically require observation and feedback. This article reviews the role of feedback in clinical medical education by drawing on current guidelines on feedback, published research and opinion on feedback in the medical education literature, plus our own personal observations. The purpose of our review is to:

1. provide an understanding of feedback within the learning process;

2. consider barriers to the feedback process;

3. consider consequences of inadequate or poorly given feedback;

4. provide practical guidelines for providing feedback within clinical placements;

5. evaluate workplace assessment;

6. consider the role of student and faculty development in the key skill of feedback.

\section{Discussion}

\section{Feedback within the learning process}

Feedback and assessment are sometimes used interchangeably, resulting in confusion surrounding feedback. Distinct from assessment, feedback presents information, rather than judgment. ${ }^{6}$ Moreover, there are theoretical differences. Feedback is formative, and an integral part of the learning process. It ensures students remain on target to reach their goals. Thus, feedback should be given regularly and early in clinical placements. Assessment, however, is summative. It comes at the end of a clinical placement and provides a judgment about how well or poorly a student has met predetermined outcomes. Although assessment at the completion of a clinical placement may be considered by clinical supervisors to provide students with adequate feedback, it is of little use to the student at this point in time. Figure 1 demonstrates feedback as an integral part of the learning cycle.

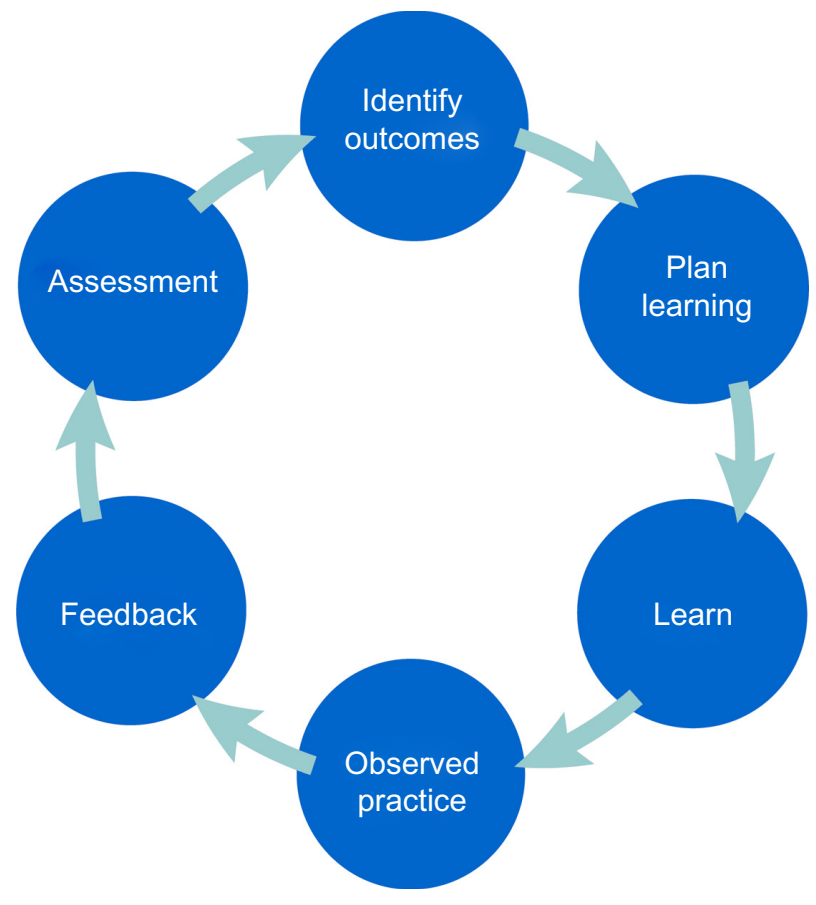

Figure I The learning cycle during clinical placements.

\section{Purpose of feedback}

Feedback acts as a continuing part of the instructional process that supports and enhances learning. ${ }^{7}$ It is part of an ongoing unit of instruction and assessment, rather than a separate educational entity. ${ }^{8} \mathrm{~A}$ core component of formative assessment and a central part of learning, ${ }^{9}$ feedback promotes learning in three ways: ${ }^{7}$

- Informs the student of their progress

- Informs the student regarding observed learning needs for improvement

- Motivates the student to engage in appropriate learning activities

\section{Efficacy of feedback}

There are many studies suggesting that the provision of formative feedback has the potential to direct student learning by reinforcing desirable learning behaviors. ${ }^{10} \mathrm{~A}$ recent meta-analysis examining the impact of feedback on clinical performance within medical education ${ }^{11}$ found that the provision of feedback had a positive effect in 106/132 (77\%) of the included studies. Feedback has the greatest impact on students' behavior when it is provided based on a specific task. ${ }^{12}$

\section{Barriers to the feedback process}

It is difficult to avoid the judgment associated with feedback. In a busy hospital ward, positive feedback is pleasing for all, but negative feedback can be both difficult and 
disappointing. There is no way to inform a student of his/her misdiagnosis of a patient without provoking some degree of disappointment. While such errors should be quickly brought to the student's attention, provision of negative feedback requires skill and understanding of the process. The desire to avoid upsetting students with negative feedback can result in what has been described as "vanishing feedback,"13 where the teacher lacks the competence to provide meaningful feedback and, consequently, avoids giving any.

Emphasis has recently been placed on the importance of exposure to the clinical environment and to role models in clinical education. ${ }^{14}$ Yet, clinical experiences, role models, and learning objectives are not enough. The entire process requires interactions and direction, which is where feedback comes into play. Feedback needs to be viewed as an absolute necessity in clinical education. While giving meaningful feedback is a learnt skill, requiring practice and planning, it is merely one part of the total process of learning clinical skills.

The most obvious explanation for the paucity of feedback in clinical education is the failure to make firsthand observations of a students' performance. Without observation, errors will go uncorrected, and good performance is not reinforced. As a result, clinical competence may not be achieved, and the ultimate goal in clinical education, patient welfare, may be compromised. Less obvious consequences of poor feedback are that some students are left with uncertainties when they begin their internship. The sense of being adrift in an unfamiliar environment is amplified by lack of feedback. Without this external feedback, some may generate their own feedback, by attaching importance to internal and external cues. ${ }^{1}$ However, there are many problems associated with an overreliance on self-assessment.

\section{Self-assessment}

Self-assessment is notoriously wrong. ${ }^{1}$ Using self-assessment, high performers tend to underestimate their own performance and lower performers overestimate ${ }^{15}$ Feedback, however, gives students the opportunity to benchmark their own self-assessment against external assessment. Often feedback is regarded as having the sole purpose of improving a student's performance. However, it also acts as a tool in cultivating self-assessment and reflection on performance.

\section{Peer feedback}

Giving feedback to peers is perceived as beneficial in development of knowledge, skills, and professional attributes. ${ }^{16}$ The practice of peer assessment and feedback can foster high levels of responsibility in students. ${ }^{16-18}$ Students who provide feedback to their peers report metacognitive gains and development of professionalism skills. ${ }^{16,18,19}$ However, concerns regarding the honesty and accuracy of peer feedback have been widely reported. ${ }^{16,18-21}$ For example, we have reported on a formative objective structured clinical examination, whereby final-year medical students were required to assess their junior peers. ${ }^{18}$ We found that while students were confident to make a judgment on a junior peer's performance by completing a standardized marking sheet and assessing each performance domain against set marking criteria, they were less able to report an accurate overall global performance and to provide accurate and constructive feedback. ${ }^{18}$ The lack of ability of students to provide constructive peer feedback has been associated with social discomfort and inadequate training. ${ }^{22}$ Even when students feel confident to provide feedback to their peers, they remain apprehensive about providing negative feedback. They have concerns over the influence that negative feedback may have on friendships, particularly when they have established long-term relationships among peers. ${ }^{16,23}$ Students are also concerned about the quality of their feedback, and their own skills in giving effective feedback. ${ }^{16}$ However, students do find using a structured method for providing feedback to peers useful. ${ }^{16,24}$

\section{Student reception of feedback}

Not unlike giving feedback, receiving feedback is not a simple, passive act. It requires honest self-reflection and a commitment to improving clinical skills. Many students are not prepared nor trained in receiving, or in accepting, feedback. Who gives the feedback may have as much impact as what the feedback is and how it is delivered. ${ }^{25}$ There can be important contextual and relational aspects of feedback. ${ }^{25}$ Accordingly, there needs to be "source credibility," whereby acceptance and effectiveness of the feedback is dependent on the credibility of the person providing the feedback. ${ }^{25}$ Credibility is determined by the nature and quality of that person's relationship with the student receiving the feedback and the person's understanding of the student's learning objectives; students' perception of their intentions; and on direct observation.

We found in a recent study of students receiving feedback from both academic and student coexaminers in a long case examination setting, that in this formal setting, students were much more receptive to receiving feedback from the academic examiner than their peer examiner. ${ }^{26}$ Students reported that they were reliant on very specific feedback from the academic examiner. Students found feedback from their peer to 
be less constructive, accurate, and helpful than the academic examiner's feedback. ${ }^{26}$ However, they were quite receptive to receiving feedback from their peer outside of the examination room in an informal setting. Although students felt that their peers had adequate knowledge to provide worthwhile feedback, they felt the quality, honesty, and accuracy of the feedback was increased when it was given away from the academic, in a more relaxed, setting. "Cognitive congruence" may allow peers to target the students' level of understanding. ${ }^{27}$ In fact, it has been suggested that student experience of receiving feedback from peers rather than academics may provide a qualitatively different learning experience, enhancing both the quantity and the meaningfulness of the feedback. ${ }^{28}$ Students respected the insight and feedback of their peers but found they were better able to listen to their peer in a less formal setting, away from the academic examiner.

\section{Consequences of inadequate or poorly given feedback} Prevalence of feedback

Students frequently complain that they are not given adequate feedback as they progress, and when it is given, it is vague and ineffective. ${ }^{4}$ Feedback following formative assessment has a powerful influence on a student's performance. However, there is a significant gap between what should be done and what happens in practice. One of the most serious deficiencies in current medical education practice is the lack of assessment and feedback based on direct observation of performance. ${ }^{29}$ Several studies have reported that assessment of directly observed performance is infrequently done as part of routine educational practice. A recent survey of US medical graduates found that during any given clinical placement, up to $40 \%$ of students were not observed performing a clinical examination. ${ }^{30}$ In another study based in the US, Kogan et $\mathrm{al}^{31}$ found that only $28 \%$ of clinical placements included a formative assessment that involved observation of student performance in the clinical setting. Daelmans et $\mathrm{al}^{32}$ reported that over a 6-month period, observation of student performance occurred in $<35 \%$ of cases. It has been suggested that in order for feedback to be accurate and constructive, direct observation of students by the same tutor in a number of patient interactions is needed. ${ }^{4}$

\section{Quality of feedback}

Additionally, the quality of feedback, when given, may be poor and often does not translate into a plan of action. ${ }^{29}$ The ability to competently take a history and examine a patient are mainstays of medical practice. ${ }^{29}$ Therefore, the ability of clinical tutors to accurately observe students' performance of history taking and physical examination and then provide effective feedback is a crucial aspect of medical training.

The key reasons that clinical tutors fail to give effective feedback may appear to be:

- too much focus on assessment, rather than feedback;

- limited space and time for recording feedback on feedback forms;

- tutors' lack of appreciation of the key role of feedback as a teaching tool;

- tutors' lack of skill in giving feedback.

\section{Practical guidelines for providing feedback within clinical placements}

As well as direct observation of learners, good feedback requires clear goals and outcomes. ${ }^{4}$ Provision of constructive feedback that details both positive and negative aspects of a student's performance is a time-consuming, and sometimes, difficult task. However, not giving feedback can have a substantial negative effect. Good performance is not reinforced and poor performance remains uncorrected. ${ }^{33}$ Negative feedback can also cause harm if not carefully relayed and could result in demotivation or deterioration in performance. ${ }^{33} \mathrm{We}$ have summarized the elements required for a successful feedback session in Figure 2. The success of a formative feedback session is dependent on three key areas: structure, format, and content. ${ }^{34}$

\section{Structure}

The feedback session should be scheduled at a time convenient for both the teacher and the student, with adequate time for both to prepare. The purpose of the meeting should be clear to the student. The location for feedback should consider confidentiality requirements for the student. The feedback provided needs to focus on knowledge, attitudes, and behaviors, particularly those observed by the assessor. Use of descriptive words helps the recipient to understand that the purpose of the session is to help improve his/her performance. The format of the session should include time for the learner to self-assess, the teacher to assess, and the joint development of an action plan. ${ }^{35}$ Documentation of the feedback session should be completed and a further session scheduled to ensure follow-up.

Attention should be given to the room setting for feedback, with seating arrangements indicating that the teacher is an ally, rather than an "assessor," with a joint goal to improve the students' performance. ${ }^{34}$ For example, a round 
1. Make direct observation where possible

2. Ask for a 'self-assessment' first

3. Be constructive

4. Provide specific detail on what needs improvement

5. Limit the feedback to two or three specific areas to work on

6. Provide detailed plan/strategy on how to achieve improvement

7. Check the student has a clear understanding on what needs improvement, and how to make the improvements

8. Plan another observation and feedback session

9. Document the session

Figure 2 Elements of a successful feedback session.

table could be used, or the chairs could be placed on the same side of the table. A climate of mutual trust and respect indicates that the teacher is trying to help the student toward his/her goals.

\section{Format}

Feedback in the clinical setting needs to be both accurate and valuable to the recipient. ${ }^{4}$ Skills, training, and experience in giving both positive and negative feedback are essential. The overall aim of the formative feedback session is to help the student improve his/her performance, and this should be made clear at the beginning of the session. The structure of the session should also be made clear to the student. Steps to include are the student's self-assessment, the teacher's assessment, and the action plan for future improvement. There are several feedback models available. Vickery and Lake ${ }^{4}$ recommend following Pendleton's ${ }^{24}$ positive critique method. An adapted version of this is displayed in Figure 3. Within most feedback models, the framework encourages self-reflection and an emphasis on positive aspects of performance. Whatever the methodology, it must not avoid giving negative feedback. When used correctly, these models make delivery of feedback easier on the assessor because these allow the student to identify and speak first about the areas needing improvement. Rather than having the assessor raise these issues first, the assessor can concentrate on providing specific examples and outlining strategies for improvement. ${ }^{4}$

\section{Content}

Structural considerations only frame the actual feedback session. When the feedback is with regard to a clinical
1. Ask the student what went well
2. Tell them what went well
3. Ask the student what could be improved
4. Tell them what could be improved

Figure 3 Feedback model.

Note: Data from Pendleton et al..$^{24}$

placement, time needs to be taken by the student and the teacher to independently prepare their respective contents. The learner should prepare by assessing his/her own learning objectives for the clinical placement, which include both the formal set objectives and his/her own additional, personal objectives. ${ }^{34}$ The environment that has been created by the teacher for feedback assists the learner to articulate his/ her achievements, needs, and challenges in attainment of objectives. The teacher, in preparation for the session, should make a concerted effort to directly observe the student's performance and ask the opinion of others on the team. This will provide the teacher with specific examples of what the student is doing well and what needs to be improved upon. Prior to the meeting, the teacher should review his/her notes and select only a few items to concentrate on during the feedback session. ${ }^{34}$

\section{Formative assessment methods}

Clinical placements and education for medical students have evolved from loosely planned clinical immersion on wards to a curriculum-based experience linked to achievement of predetermined competencies. Indeed, workplace-based assessment offers the optimal setting for determining clinical competence and performance. ${ }^{36,37}$ That is, the student should be directly observed while performing clinical activities. These include observation of clinical skills, including communication and history taking, with attention to students' accuracy and effectiveness. Other activities that require observation and feedback include informal brief case presentations during ward rounds and formal long case presentations.

In Australia and the UK, unlike in the US and Canada, the clinical long case examination is often used as a high-stakes assessment within medical education, both in undergraduate and college programs. ${ }^{38}$ The long case examination is used at Sydney Medical School as a barrier examination for final-year medical students. Formative long case examinations that mirror the process, with the addition of feedback, are used in preparation for these high-stakes examinations. The total time taken for 
a long case examination is 1 hour and 40 minutes. In the formative examinations, students spend 1 hour taking an unobserved history and undertaking a physical examination of a patient, then 20 minutes preparing their presentation and discussion, and the next 20 minutes presenting and discussing the case with the examiners. Defined criteria are used to assess students on six marking domains, comprising both "Case Presentation" and "Case Discussion," as outlined in Table 1. The "marking criteria" consist of a five-point scale, ranging from "very poor performance" to "much better than expected," as outlined in Table 2. To pass the examination, a student must achieve a minimum of "expected standard" in at least two of the three domains in both "Case Presentation" and "Case Discussion” (Table 1).

In the formative long case, following presentation of their case, 5 minutes are additionally allocated for providing feedback to the student.

Workplace-based assessments have been reshaped and formalized in recent years to suit student clinical placements and better prepare students for summative assessments. ${ }^{39}$ There are an increasing number of formative assessment methods designed to provide feedback based on observation of students' performance on clinical placement. In fact, on the wards it may only be practicable to observe a short "slice" of a long case (eg, physical examination only, or history taking only). The short "slice" of a long case has been formalized into a mini-clinical evaluation exercise, or "mini-CEX." 40,41 The mini-CEX is carried out by students on the wards with a real patient. It generally takes the form of an observed focused history taking or focused physical examination. ${ }^{36}$ Mini-CEX is widely used in US, UK, and Australian medical schools. The total time required for a mini-CEX is 20 minutes, which includes time for verbal feedback, written comments, and marking of set criteria. ${ }^{40}$ In order to establish reliability, multiple mini-CEX encounters are required. Ten to eleven miniCEXs are sufficient, with minimal gain in consistency beyond that number. ${ }^{41}$ However, for the mini-CEX to be assessed effectively, teachers need training, ${ }^{34}$ and unfortunately, many clinicians are not comfortable with directly observing, rating, and giving feedback to students.

Whatever the method of assessment used, the information given as feedback can be used by the student to "confirm, add to, overwrite, turn, or restructure information in

Table I Marking domains in the long case

\begin{tabular}{ll}
\hline Case presentation & Case discussion \\
\hline I. History & I. Differential diagnosis and investigation \\
2. Examination & 2. Management \\
3. Summary and problem list & 3. Impact of illness on patient and family \\
\hline
\end{tabular}

Table 2 Marking criteria in the long case

\begin{tabular}{lllll}
\hline Poor & Short of & Expected & Better than \\
performance & standard & standard & $\begin{array}{l}\text { Much better } \\
\text { expected }\end{array}$ & than expected \\
\hline
\end{tabular}

memory, whether that information is domain knowledge, meta-cognitive knowledge, belief about self and tasks, or cognitive tactics and strategies." ${ }^{42}$ To help make the assessment activity worthwhile and to ensure that this feedback fulfills its purpose, students need:

- clear outcomes,

- an indication of their performance against these outcomes,

- guidelines on how to improve.

\section{Clear outcomes}

It is critical that students are provided with clearly defined outcomes. If the outcomes are not clearly articulated, then students cannot be sure of what they need to achieve. Without outcomes, students are less likely to engage in properly targeted action. ${ }^{43}$ Having clear outcomes increases the likelihood that students will seek and receive feedback, particularly if they have a shared commitment to their achievement. ${ }^{44}$ A clear understanding of desired practice or competence is needed in order to seek feedback and focus on the task of achieving competence.

\section{Indication of performance against outcomes}

Concrete information needs to be provided from the assessment of the performance benchmarked against the outcomes. This requires clear indicators of whether the task has been completed properly. Often, clinical educators are reluctant to provide honest feedback, particularly when performance is poor. Clearly defined marking criteria and marking domains make it easier to provide guidance based strictly on the observed performance, rather than the tutor's interpretations.

With the use of peer assessment and feedback, the faculty's main concern is the level of agreement between their own marking and the students' marking. ${ }^{23}$ A meta-analysis of 48 quantitative peer assessment studies on peer assessment revealed that peer assessment in medically related subjects had a tendency for poor agreement compared to the same in nonmedical subjects. ${ }^{23}$ The key factor influencing students' accuracy in assessment of their peers was identified as the clarity of the assessment criteria being used. ${ }^{23}$

\section{Guidelines on how to improve}

From the perspective of the student, it is important to know what actions need to be taken in order to close the gap 
between actual and desired performance. Students need specific information about how to achieve the desired learning outcomes. Precise, descriptive wording is needed. Behaviors that can be changed should be the focus of the feedback, not characteristics of the person. ${ }^{45}$ Very clear examples should be provided. ${ }^{33}$ The extent of feedback should be limited to what can be absorbed by the student in that session..$^{45,46}$

\section{The role of medical schools in developing teaching skills for teachers and students}

\section{The need for faculty development}

Clinical placements operate on the assumption that clinical and academic staff members possess sufficient levels of knowledge, skills, and attitudes in competencies required for teaching and assessment. ${ }^{29}$ Yet, most appointments in medicine are typically based on a combination of relevant professional qualifications and experience in research. Clinicians and academics alike are rarely equipped with evidence of teacher training or qualifications in medical education. As the evidence on good teaching accumulates, poor teaching practices are highlighted. There is little evidence to suggest that teaching experience alone makes a good teacher. ${ }^{47}$ Teaching in higher education is too important to be left to chance. ${ }^{48}$ Faculty development that promotes the professional aspect of teaching should be an integral aspect of medical schools.

McLean et $\mathrm{al}^{49}$ suggest that there should be minimum requirements and standards of practice for medical teachers and educators. The authors suggest that to professionalize the practice of teaching, the following are needed:

- Faculty development for academics as an integral part of the mission statement of medical schools.

- An institutional culture that recognizes and rewards teaching excellence and scholarship.

- Participation in formal training for those who teach students, eg, hospital clinicians.

- Mandatory teaching qualifications for university appointments and promotions of those on the educator/teaching trajectory.

Workshops provide a useful mechanism for training faculty in teaching, assessment, and feedback skills ${ }^{46}$ and they can be scheduled at a time to suit busy clinicians. They can highlight the theories of adult learning, applying practical aspects of clinical teaching strategies and opportunities for practice. In Australia, there is now a well-renowned "Teaching on the Run Program" for clinicians involved in teaching. ${ }^{50}$ The Teacher Training course, delivered as a six-module program over 18 hours, provides theoretical background, practical examples, and active participation for medical students in a range of activities, including skills related to teaching, assessment, and training in the delivery of effective feedback in the clinical context. ${ }^{51}$ Although it does not provide a formal qualification in teaching, it provides an effective way to assist busy hospital clinicians to develop skills in teaching and feedback.

\section{The need for student development in feedback skills}

Skills in peer teaching, assessment, and feedback are now increasingly documented internationally as required graduate attributes for medical students. The Australian Medical Coun$\mathrm{cil}^{52}$ requires a graduate to be able to "Demonstrate lifelong learning behaviors and fundamental skills in educating colleagues," and the UK's General Medical Council ${ }^{53}$ requires a graduate to be able to "function effectively as a mentor and teacher." Medical practitioners are expected to supervise, teach, facilitate, assess, and provide feedback to colleagues; contribute to the teaching of future generations of medical students; and be skilled in lifelong learning. Although giving feedback is an essential component of a lifelong career in medicine, it is an area of professionalism where junior doctors often feel ill prepared on entering the workforce. ${ }^{3-5,19}$ While descriptions of peer-assisted learning are abundant in literature, there remains limited literature about formal attempts to facilitate the development of medical students' teaching, assessment, and feedback skills. ${ }^{20,54} \mathrm{~A}$ recent systematic review covering the years 2002-2012 found 19 reported peer-assisted learning activities within undergraduate medical courses; yet, only two "stand alone" teacher training courses were found. ${ }^{20}$

We conducted a recent study, involving 94 senior medical students, who were required to assess their peers, alongside an academic coexaminer in the formative long case clinical examinations. ${ }^{16}$ In preparation for the activity, students received 1 hour of training that included explanation of marking domains and marking criteria, plus specific instructions on how to provide feedback to their colleagues using the Pendleton's positive critique method. ${ }^{23}$ On completion of the activity, students reported feeling inadequately prepared to provide constructive feedback. They felt that further training would have enhanced their learning experience. ${ }^{16}$ Although this study highlighted the professional and educational benefits of participating in a peer-assisted learning program, it also highlighted that the ability to assess and provide feedback is a learnt skill, requiring an appropriate level of training.

In Australia, there are two well-described teacher training programs for medical students at The University of Sydney ${ }^{51}$ and the University of Western Australia. ${ }^{55}$ However, both of 
these programs require only voluntary student participation. Some universities, such as The University of Cambridge, provide teacher training for medical students, which is compulsory and embedded into their professional development curriculum. ${ }^{56}$ Perhaps, consideration should be given to formalizing development of skills in teaching, assessment, and feedback for medical students.

\section{Conclusion}

Feedback is an absolutely essential component of the learning process. Effective and regular feedback has the potential to reinforce good practice and motivate the learner to work toward his/her desired outcome. Unfortunately, skills in giving and receiving feedback are rarely taught to students in medical school. Similarly, clinicians who teach within medical education often lack these skills. Ensuring regular feedback for medical students on clinical placements should be an integral part of the curriculum, particularly when designing or revising curricula. To be effective, the teaching of feedback skills should form part of student and faculty professional development programs. When both students and teachers understand the purpose and structure involved in feedback, the efficacy of the educational process is increased.

\section{Disclosure}

The authors report no conflicts of interest in this work.

\section{References}

1. Van den Berg I, Admiraal W, Pilot A. Peer assessment in university teaching: evaluating seven course designs. Assess Eval High Educ. 2006;31(1):19-36.

2. Taras M. Summative and formative assessment - some theoretical reflections. Br J Educ Stud. 2005;53:466-478.

3. Gordon J. ABC of learning and teaching in medicine: one to one teaching and feedback. BMJ. 2003;326:543-545.

4. Vickery AW, Lake FR. Teaching on the run tips. 10: giving feedback. Med J Aust. 2005;183(5):267-268.

5. Pencheon D. Development of generic skills (career focus). BMJ. 1998;317:2-3.

6. Hyman RT. Improving Discussion Leadership. New York: Teachers College Press; 1980.

7. Shepard LA. The role of assessment in a learning culture. Educ Res. 2000;29:4-14.

8. Hattie J, Timperley H. The power of feedback. Rev Educ Res. 2007;77: 81-112.

9. Branch WT, Paranjape A. Feedback and reflection: teaching methods for clinical settings. Acad Med. 2002;77:1185-1188.

10. Gibbs G. Using assessment strategically to change the way students learning. In: Brown S, editor. Assessment Matters in Higher Education. Choosing and Using Diverse Approaches. Buckingham: Society for Research into Higher Education and Open University Press; 1999:210.

11. Veloski J, Boex JR, Grasberger J, Evans A, Wolfson DB. Systematic review of the literature on assessment, feedback, and physician's clinical performance: BEME Guide No 7. Med Teac. 2006;28:117-128.
12. Hattie JA. Influences on Student Learning. New Zealand: University of Auckland; 1999.

13. Ende J. Feedback in clinical medical education. Med Educ. 1983;250(6): 777-781.

14. Passi V, Johnson S, Peile E, Wright S, Hafferty F, Johnson N. Doctor role modelling in medical education: BEME Guide No. 27. Med Teach. 2013;35:1422-1436.

15. Davis DA, Mazmanian PE, Fordis M, Vvan Harrison R, Thorpe KE, Perrier L. Accuracy of physician self-assessment compared with observed measures of competence: a systematic review. JAMA. 2006;296:1094-1102.

16. Burgess A, Roberts C, Black K, Mellis C. Senior medical student perceived ability and experience in giving peer feedback in formative long cases examinations. BMC Med Educ. 2013;13:79.

17. Keaten JA, Richardson ME. A field investigation of peer assessment as part of the student group grading process. Paper presented at: Western Speech Communication Association Convention; 1992; Albuquerque, NM. [Conference Proceedings].

18. Burgess A, Clark T, Chapman R, Mellis C. Senior medical students as peer examiners in an OSCE. Med Teach. 2012;35:58-62.

19. Topping KJ. Trends in peer learning. Educ Psychol. 2005;25(6): 631-645.

20. Burgess A, McGregor D, Mellis C. A systematic review of peer assisted learning (PAL) in medical schools. BMC Med Educ. 2014;14:115.

21. Burgess A, Roberts C, Black K, Mellis K. Student ability to assess their peers in long case clinical examination. IJOCS. 2014;8:1.

22. Cassidy S. Developing employability skills: peer assessment in higher education. Educ Train. 2006;48(7):508-517.

23. Falchikov N, Goldfinch J. Student peer assessment in higher education a meta-analysis comparing peer and teacher marks. Rev Educ Res. 2000;70(3):287-322.

24. Pendleton D, Schofield T, Tate P, Havelock P. The Consultation: An Approach to Learning and Teaching. Oxford: Oxford University Press; 1984.

25. Telio S, Ajjawi R, Regehr G. The "educational alliance" as a framework for reconceptualizing feedback in medical education. Acad Med. Epub November 18, 2014.

26. Burgess A, Mellis C. Receiving feedback from peers: medical students' perceptions. Clin Teach. In press 2015.

27. Moust JC, Schmidt HG. Effects of staff and student tutors on student achievement. Higher Educ. 1994;28:471-482.

28. Nestel D, Kidd J. Peer assisted learning in patient-centred interviewing: the impact on student tutors. Med Teach. 2005;27:439-444.

29. Holboe ES, Yepes M, Williams F, Huot SJ. Direct observation of competence training: a randomized controlled trial. Ann Intern Med. 2004; 140:874-881.

30. Association of American Medical Colleges. Medical School Graduation Questionnaire: 2012. All School Summary Report; 2014. Available from: https://www.aamc.org/data/gq/allschoolsreports. Accessed February 17, 2015.

31. Kogan JR, Bellin LM, Shea JA. Implementation on the mini-CEX to evaluate medical students' clinical skills. Acad Med. 2000;77:1156-1157.

32. Daelmans HE, Hoogenboom RJ, Donker AJ, Scherpbier AJ, Stehouwer CD, Van der Vleuten CO. Effectiveness of clinical rotations as a learning environment for achieving competences. Med Teach. 2004;26(4):305-312.

33. Cantillon P, Sargeant J. Giving feedback in clinical settings. BMJ. 2008;337:a1961.

34. Bienstock JL, Katz NT, Cox SM, Hueppchen N, Erickson S. To the point: medical education reviews - providing feedback. Am J Obstet Gynaecol. 2007;196(6):508-513.

35. Torre DM, Sebastian JL, Simpson DE. Learning activities and highquality teaching: perceptions of their-year IM clerkship students. Acad Med. 2003;78:812-814.

36. Mellis CM. Optimizing training: what clinicians have to offer and how to deliver it. Paediatr Respir Rev. 2008;9:105-113. 
37. Lake FR. Teaching on the run tips 8: assessment and appraisal. Med $J$ Aust. 2005;182:580-581.

38. Wass V, Jones R, Van der Vleuten C. Standardized or real patients to test clinical competence? The long case revisited. Med Educ. 2001;35: 321-325.

39. Weinstein DF. Feedback in clinical education: untying the Gordian Knot. Acad Med. Epub November 18, 2014.

40. Davies H, Howells R. How to assess your specialist registrar. Arch Dis Child. 2004;89:1089-1093.

41. Norcini J, Burch V. Workplace-based assessment as an educational tool: AMEE Guide No 31. Med Teach. 2007;29(9-10):855-871.

42. Winnie PH, Butler DL. Student cognition in learning from teaching. In: Husen T, Postlewaite TN, editors. International Encyclopedia of Education. Oxford, UK: Pergamon; 1994:5738-5745.

43. Bargh JA, Gollwitzer PM, Lee-Chia A, Barndollar K, Trotscel R. The automated will: nonconscious activation and pursuit of behavioural goals. J Pers Soc Psychol. 2001;81:1014-1027.

44. Locke EA, Latham GP. A Theory of Goal Setting and Task Performance. Englewood Cliffs, NJ: Prentice Hall; 1990.

45. Wood B. Feedback: a key feature of medical training. Radiology. 2000;2015:17-19.

46. Krakov SK. Giving feedback. In: Dent JA, Harden RM, editors. A Practical Guide for Medical Teachers. 3rd ed. London: Churchill Livingstone Elsevier; 2009:895.

47. Norton L, Richardson JTE, Hartley J, Newstead S, Mayes J. Teachers' beliefs and intentions concerning teaching in higher education. Higher Educ. 2005;50:537-571.
48. Brown S. The institute for learning and teaching and UK approaches to accrediting teaching: looking to the future. Med Teach. 2000;22(5): 513-516.

49. McLean M, Cilliers F, Van Wyk JM. AMEE educational guide no 33, faculty development: yesterday, today and tomorrow. Med Teach. 2008; 30(6):555-584.

50. Tell Centre. Teaching on the Run; 2014. Available from: http:// tellcentre.org/. Accessed December 6, 2014

51. Burgess A, Black K, Chapman R, Clark T, Roberts C, Mellis C. Clinical teaching skills for students: our future educators. Clin Teach. 2012;9:312-316

52. Australian Medical Council. Good Medical Practice. A Code of Conduct for Doctors in Australia; 2012. Available from: http://www.amc.org. au/index.php/about/good-medical-practice. Accessed December 13, 2014.

53. General Medical Council. Tomorrows Doctor Outcomes and Standards. London: General Medical Council; 2009.

54. Dandavino M, Snell L, Wiseman J. Why medical students should learn how to teach. Med Teach. 2007;29:558-565.

55. Silbert BI, Lake FR. Peer-assisted learning in teaching clinical examination to junior medical students. Med Teach. 2012;34(5):392-397.

56. School of Clinical Medicine, University of Cambridge. [homepage on the Internet]. Standard Clinical Course (MB BChir Standard) http://www.medschl.cam.ac.uk/education/courses/standard/. Accessed April 13, 2015.
Advances in Medical Education and Practice

\section{Publish your work in this journal}

Advances in Medical Education and Practice is an international, peerreviewed, open access journal that aims to present and publish research on Medical Education covering medical, dental, nursing and allied health care professional education. The journal covers undergraduate education, postgraduate training and continuing medical education

\section{Dovepress}

including emerging trends and innovative models linking education, research, and health care services. The manuscript management system is completely online and includes a very quick and fair peer-review system. Visit http://www.dovepress.com/testimonials.php to read real quotes from published authors.

Submit your manuscript here: http://www.dovepress.com/advances-in-medical-education-and-practice-journal 